\title{
Blood-borne one year on
}

It is pleasing to learn that David Croser, who penned such an effective opinion piece for us last year on the plight of dentists with blood-borne viruses, Written off, ${ }^{1}$ recently received a letter from the Chief Dental Officer for England. This reports that the UK Advisory Board for Healthcare Workers Infected with Blood-borne Viruses (UKAP), the Expert Advisory Group on AIDS (EAGA) and the Advisory Group on Hepatitis have recently decided to review current policies on healthcare workers infected with blood-borne viruses and will meet this autumn. A specific issue they will consider is the current restrictions on primary care dentists with HIV. Once their review is complete, the committees will then make recommendations to the Chief Medical Officers.

For such a review to take place was one of the pleas that I also made in my editorial in the same issue, ${ }^{2}$ and which was given so much emotional power by our HIV positive GDP colleague in relating his personal experiences in a later issue. ${ }^{3}$ Additionally it was clearly supported by the BDA Representative Body in its motion in January this year urging the BDA to continue pressure to rectify this iniquitous situation for members of our profession. Clearly, therefore, this is an important step forwards and is welcomed.

Many readers made contact following the publication of the GDP's disturbing story ${ }^{3}$ expressing their horror, sadness and sympathy. I am pleased to be able to report that he has kept in touch with us and remains well. He has also been doing as much as he can on a personal basis to improve matters for colleagues including being in contact with his own MP and with the Rt Honourable Lord Smith of Finsbury (former MP, Chris Smith), who in turn has written to the Secretary of State for Health. One can only hope that the Secretary too will be in touch with the Chief Medical Officers in relation to the advice they are soon to receive from the new review.

There remain two main aspects to this whole area of concern. One is the evidence-base, from which we should be able to draw scientific, logical conclusions on the best way forwards. The other is what happens if one is effectively put out of work by the interpretations of those conclusions; as dentists working clinically currently are.

As we have learnt in these columns from correspondence supporting last year's publications, the evidence-base is clear. There is no further evidence of any new transmission from a dentist to a patient specifically of HIV infection since the one still unexplained case in the USA in 1990. None. Surely by now, out of all the millions, no doubt billions of courses of dental treatment provided worldwide, if it was a threat, even a theoretical threat, there would have been one case? The HIV positive GDP wrote by his own admission that he had probably been unknowingly infected (and untreated) for some eight years before being diagnosed. ${ }^{3}$ No evidence at all of any transmission to patients. How many other colleagues are in a similar situation now? Whispered conversations in corridors in the past twelve months suggest that others are in that position but dare not even get tested, which therefore denies them treatment, for the fear that they will lose their livelihood too. How does that protect the public?

Which brings me to the other aspect; being put out of work. We have also learnt in the intervening time that other countries allow HIV infected dentists to continue to work, under sensible conditions that protect all concerned; the US and Australia being excellent examples., ${ }^{4,5}$

Curiously, and with care, I cannot help but make some observations between this matter and the current, awful, foot and mouth virus tribulations in the UK. While there is no complete indication as yet as to how the leak from the research facility happened, it seems that there is a link. The immediate logical question on many commentators' lips has then been 'who is to blame?' with the implied follow-up of 'who pays?' My guess is that the vast majority of people would see it as being wholly reasonable that farmers affected by the ban on moving livestock, which strikes at the heart of their business, should be compensated by the government as happened previously. This is not because it was the government's fault but because regulations, laws and restrictions laid down by the state for the benefit of all meant that livelihoods were directly disadvantaged. If the state declares for whatever reason that a person has to cease their work it must surely be beholden on the state to also provide for that person to be compensated. The state cannot have it both ways. As a principle this should stand irrespective of circumstance, but in the event that as a result of reviewing the evidence-base, barring of professional practice continues on what will inevitably be construed as a political decision, then I believe there is neither a foot, nor a mouth, on which the state can morally stand.

Stephen Hancocks OBE Editor-in-Chief

1. Croser D. Written off. Br Dent J 2006; 201: 497-499.

2. Hancocks $S$. Losing your livelihood just twenty minutes from now (Editorial). BrDent J 2006; 201: 485.

3. Anon. This was something that happened to someone else. An HIV positive dentist explains. Br Dent J 2006; 201: 697-698.

4. Marianos D. Review the evidence (Letter). Br Dent J 2007; 202: 2-3.

5. Condon G. A worldwide issue. (Letter). Br Dent J 2007; 202: 435-436.

DOI: $10.1038 /$ bdj.2007.963 